\title{
ENVIRONMENTAL POLICIES IN A STAGNANT ECONOMY
}

\author{
Masako Ikefuji \\ Yoshiyasu Ono
}

December 2020

The Institute of Social and Economic Research Osaka University 


\title{
Environmental policies in a stagnant economy*
}

\author{
Masako Ikefuji \\ University of Tsukuba; ISER, Osaka University
}

\author{
Yoshiyasu Ono \\ ISER, Osaka University
}

December 7, 2020

\begin{abstract}
Using a dynamic optimization model of a monetary economy where persistent unemployment can prevail, we examine the effects of environmental policies on consumption and pollution emissions in a full-employment and a stagnant economy. If full employment prevails, environmental policies such as environmental tax and public pollution abatement naturally crowd out commodity production and hence decrease consumption. However, if unemployment appears, they stimulate consumption and production by increasing total employment and mitigating deflation, thus yielding additional pollution emissions. Net pollution emissions may eventually increase. The optimal environmental policy mix is also examined.
\end{abstract}

JEL Classification: E24, O42, Q58.

Keywords: Secular stagnation, Unemployment, Public abatement, Environmental tax

${ }^{*}$ The authors are grateful to the attendees at the conferences of SURED 2014 in Ascona, EEA-ESEM 2014 in Toulouse, and Public Economic Theory 2014 in Seattle; seminars at the University of Paris Ouest-Nanterre La Défense 2014 and National Institute for Environmental Studies 2018; the Macroeconomic Workshop 2019 at Toyo University; and International Institute of Public Finance 2020 (virtually). This work was financially supported by the Asahi Glass Foundation, JSPS KAKENHI Grant (JP15H05728, JP20H01477, JP20H05631) and the Program of the Joint Usage/Research Center for Behavioral Economics at the Institute of Social and Economic Research (ISER), Osaka University. E-mail addresses: ikefuji.masako.gn@u.tsukuba.ac.jp (Ikefuji), ono@iser.osaka-u.ac.jp (Ono). Corresponding author: Masako Ikefuji. Faculty of Humanities and Social Sciences, University of Tsukuba, 1-1-1 Tennodai, Tsukuba, Ibaraki, 305-8571 Japan; ISER, Osaka University, 6-1 Mihogaoka, Ibaraki, Osaka 567-0047, Japan 


\section{Introduction}

It has long been recognized that the threat of global warming is increasing. In 2018, nearly $50 \%$ of human deaths and $90 \%$ of economic damage (estimated at US\$ 123 billion) were due to climatological, hydrological, or meteorological disasters (EM-DAT database, OFDA/CRED). These are considered to have been caused by global warming. To stabilize greenhouse gas concentrations in the atmosphere and mitigate their threat, urgent countermeasures are needed.

However, since the international financial crisis of 2008, most countries have been suffering from low (or even negative) economic growth with a lasting output gap (OECD, 2019; IMF, 2019), and environmental costs appear to be a significant burden on stagnant economies. IPCC (2014) expects an annual reduction of consumption growth by $0.04 \%$ to $0.14 \%$ with mitigation policies over the current century relative to annual consumption growth without mitigation policies. Currently, the CO2 reduction commitments of most countries are insufficient and global emissions continue to increase.

Given this situation, we investigate the effects of environmental policies, such as emission tax and public pollution abatement, on consumption, pollution emissions and welfare. We do so in a full-employment and a stagnant economy context and compare the effects in the two cases.

In the literature, much attention has been paid to the effects of environmental policies on economic performance. Among others, Nielsen et al. (1995) assume that unemployment stems from the monopoly power of unions in an endogenous growth model, and show that increased environmental concern and increased labor market distortions raise the optimal environmental tax and lower economic growth. In the literature on the double dividend hypothesis, which means that environmental tax reforms not only improve environmental quality but also stimulate economic performance, Koskela et al. (1998) model a wage employment bargaining process between trade unions and firms and explore the 
case where increasing an energy tax drives firms to replace dirty energy by labor for production and improves both employment and environment. Koskela and Schöb (1999) show that the effect of a revenue-neutral green tax reform on employment depends on the structure of income taxes and unemployment benefits. Bovenberg and van der Ploeg (1998) apply the job matching mechanism to the double dividend issue. They find that an energy tax promotes job matching by lowering the income of the unemployed who work in the informal sector and improves production. Bye (2002) adopts a dynamic model with trade union wage negotiations and shows that the effect of an environmental tax reform on the double dividend may differ in the short and long runs.

While those researchers treat unemployment as caused by job matching and trade union negotiations, many countries, including EU member states, Japan and the United States, have been facing involuntary unemployment with aggregate demand shortages since the global financial crisis of 2008. We consider this case using the model of Ono (1994, 2001), where people's liquidity (or wealth) preference causes aggregate demand shortages and involuntary unemployment to appear in the steady state. ${ }^{1}$

In this setup we analyze the effects of environmental policies on consumption and pollution emissions in a full-employment and a stagnant economy. ${ }^{2}$ In a full-employment economy, the policies lower pollution and consumption, or in other words, pollution abatement comes at the expense of lower consumption. In a stagnant economy, by contrast, they not only abate pollution but also create employment and thereby stimulate consumption. The expansion in consumption will yield extra pollution, which may dominate the first-stage abatement. If the abatement technology is high, however, the first-stage abatement dominates the extra pollution and people can enjoy both business recovery

\footnotetext{
${ }^{1}$ This type of model has recently expanded in the literature, including Ono and Ishida (2014), Michaillat and Saez (2014), Michau (2018), and Illing et al. (2018).

${ }^{2}$ Many studies have examined the effects of public abatement activities in a static (Ligthart and van der Ploeg, 1999; Mayeres and Proost, 2001) and a dynamic framework (Bovenberg and Heijdra, 2002; Pérez and Ruiz, 2007; Itaya, 2008; Fullerton and Kim, 2008; Angelopoulos et al., 2013; Beladi et al., 2013). However, none of them consider unemployment.
} 
and a better environment.

The remainder of the paper is organized as follows. Section 2 sets up the model and characterizes the dynamics of the economy. Section 3 investigates the effects of environmental policies in a full-employment economy. Section 4 considers the case in which aggregate demand shortages and involuntary unemployment appear in a steady state and shows the effects of the policies. Section 5 examines the first-best environmental policy mix in a stagnant and a full-employment economy by taking into account the possibility of a transition from stagnation to full employment thanks to the environmental policies. Finally, Section 6 concludes.

\section{The model}

\section{The household}

We consider an economy populated by identical households whose population size is normalized to unity. Each household's lifetime utility is

$$
U\left(c_{t}, m_{t}, z_{t}\right)=\int_{0}^{\infty}\left[u\left(c_{t}\right)+v\left(m_{t}\right)-\delta\left(z_{t}\right)\right] \exp (-\rho t) d t
$$

where $u\left(c_{t}\right)$ is the utility of consumption $c_{t}, v\left(m_{t}\right)$ is the utility of real money holdings $m_{t}$, and $\delta\left(z_{t}\right)$ is the disutility of pollution $z_{t}$. The functions $u(c), v(m)$, and $\delta(z)$ satisfy the following properties:

$$
u^{\prime}>0, \quad u^{\prime \prime}<0 ; \quad v^{\prime}>0, \quad v^{\prime \prime}<0 ; \quad \delta^{\prime}>0, \quad \delta^{\prime \prime}>0 .
$$

The stock budget equation of the household is

$$
a_{t}=b_{t}+m_{t}
$$


where $a_{t}$ and $b_{t}$ respectively denote total assets and equities. ${ }^{3}$ The flow budget equation is

$$
\dot{a}_{t}=r_{t} a_{t}-R_{t} m_{t}+w_{t} \ell_{t}-c_{t}-\theta_{t},
$$

where $r_{t}$ and $R_{t}\left(=r_{t}+\pi_{t}\right.$ when the inflation rate is $\left.\pi_{t}\right)$ are the real and nominal interest rates, $w_{t}$ is the real wage, $\ell_{t}$ is the realized amount of labor supply, and $\theta_{t}$ is a lump-sum tax. Each household inelastically supplies all labor endowment, which is normalized to unity. Since we consider the possibility of unemployment, $\ell_{t}$ is given by the short side of labor demand $\ell_{t}^{d}$ and labor supply 1 :

$$
\ell_{t}=\min \left(\ell_{t}^{d}, 1\right)
$$

The household maximizes (1) subject to (2) and (3). The first-order optimal condition is

$$
\rho+\eta \frac{\dot{c}_{t}}{c_{t}}+\pi_{t}=R_{t}=\frac{v^{\prime}\left(m_{t}\right)}{u^{\prime}\left(c_{t}\right)}
$$

where $\eta \equiv-u^{\prime \prime}\left(c_{t}\right) c_{t} / u^{\prime}\left(c_{t}\right)$ is the elasticity of the marginal utility of consumption. The transversality condition is

$$
\lim _{t \rightarrow \infty} \lambda_{t} a_{t} \exp (-\rho t)=0
$$

where $\lambda_{t}$ denotes the shadow price of asset $a_{t}$.

\section{The firm}

In period $t$, the representative firm produces $y_{t}$ with the following production technology:

$$
y_{t}=A \ell_{p, t}
$$

\footnotetext{
${ }^{3}$ It is shown in the market section of the model that $b_{t}$ is zero because the technology of the firm sector is linear-homogeneous.
} 
where $\ell_{p, t}$ is the labor employed to produce commodities and $A$ is constant labor productivity. The production process is assumed to yield a proportional amount of pollution emissions:

$$
e_{t}=\epsilon y_{t}
$$

The government imposes a real tax $\tau$ per unit of pollution emissions. The firm can reduce the amount of pollution $e_{a}$ with homogeneous abatement technology:

$$
\begin{aligned}
& e_{a}=\Phi\left(\ell_{a}, e\right)=e \Phi(h, 1) \equiv e \varphi(h), \quad h \equiv \frac{\ell_{a}}{e} \\
& \varphi^{\prime}>0, \quad \varphi^{\prime \prime}<0, \quad 0 \leq \varphi \leq 1, \quad \varphi(0)=0, \quad \varphi(\infty)=1,
\end{aligned}
$$

where $h$ and $\varphi(h)$ respectively represent the ratio of labor employed in the abatement sector to pollution emissions and the reduction rate of emissions.

Given emission tax $\tau$ and real wage $w_{t}$, the firm chooses labor for commodity production $\ell_{p}$ and labor for pollution abatement $\ell_{a}$ to maximize profits:

$$
A \ell_{p, t}-w_{t}\left(\ell_{p, t}+\ell_{a, t}\right)-\tau\left(1-\varphi\left(\frac{\ell_{a, t}}{e_{t}}\right)\right) \epsilon A \ell_{p, t}
$$

Because $e_{t}$ satisfies (8), the first-order optimal conditions are

$$
\begin{aligned}
& A=w_{t}+\tau \epsilon A\left(1-\varphi\left(h_{t}\right)+\varphi^{\prime}\left(h_{t}\right) h_{t}\right), \\
& w_{t}=\tau \varphi^{\prime}\left(h_{t}\right)
\end{aligned}
$$

from which we immediately obtain

$$
w_{t}= \begin{cases}A\left(1-\tau \epsilon\left(1-\varphi\left(h_{t}\right)+\varphi^{\prime}\left(h_{t}\right) h_{t}\right)\right)=\tau \varphi^{\prime}\left(h_{t}\right) \Rightarrow h=h(\tau) & \text { if } \tau>0 \\ A \quad \text { and } \ell_{a}=0 & \text { if } \tau=0\end{cases}
$$


If $\tau \varphi^{\prime}\left(h_{t}\right)$ that satisfies the first equation in (11) is higher (lower) than the $w_{t}$ determined in the labor market, the firm will hire infinite (zero) labor. Thus, $w_{t}$ is determined so that it satisfies (10) and (11). From (9) and (11), we find

$$
h^{\prime}(\tau)>0 .
$$

\section{The government}

From (8) and (9), the amount of pollution emitted by the firm is

$$
e_{t}-e_{a, t}=(1-\varphi(h)) e_{t}
$$

The government reduces the amount of pollution $e_{g}$ by utilizing labor $\ell_{g}$ with the following abatement technology: ${ }^{4}$

$$
e_{g}=\psi\left(\ell_{g}\right) ; \quad \psi^{\prime}>0, \quad \psi^{\prime \prime}<0, \quad \psi(0)=0
$$

Then the amount of net pollution emissions $z_{t}$ is

$$
z_{t}=(1-\varphi(h(\tau))) e_{t}-\psi\left(\ell_{g, t}\right)
$$

For example, the public sector plants trees to absorb the $\mathrm{CO} 2$ emitted from the private sector or disposes of industrial contaminated waste. The employment for public abatement is financed by the emission $\operatorname{tax} \tau$ and lump-sum $\operatorname{tax} \theta$,

$$
w \ell_{g, t}=\tau\left(1-\varphi\left(h_{t}\right)\right) e_{t}+\theta_{t},
$$

\footnotetext{
${ }^{4}$ In Appendix B, we consider an alternative abatement technology of the government. We show that the following arguments hold under this technology as well.
} 
and hence can arbitrarily choose $\ell_{g, t}$ by changing $\theta_{t}$.

\section{The market}

The commodity market equilibrium implies

$$
c_{t}=y_{t}=A \ell_{p, t} .
$$

From (8) and (15),

$$
e_{t}=\epsilon c_{t} .
$$

Thus, the net pollution emissions $z_{t}$ given by (14) and employment for private abatement $\ell_{a}$ that satisfies (9) are respectively

$$
\begin{aligned}
& z_{t}=(1-\varphi(h(\tau))) \epsilon c_{t}-\psi\left(\ell_{g, t}\right), \\
& \ell_{a, t}=h(\tau) \epsilon c_{t} .
\end{aligned}
$$

The money and equity markets always satisfy

$$
\frac{M_{t}}{P_{t}}=m_{t}, \quad b_{t}=0,
$$

in which nominal money supply $M_{t}$ is, for simplicity, assumed to be constant and the total value of $b_{t}$ is zero because the firm earns zero profits with the linear-homogeneous technology.

It is assumed that, in the labor market, the nominal wage is flexible under full em- 
ployment and sluggish in the presence of unemployment. Therefore, ${ }^{5}$

$$
\left\{\begin{array}{l}
W_{t} \text { is perfectly flexible if } \ell_{d, t}=1 \\
\frac{\dot{W}_{t}}{W_{t}}=\gamma\left(\ell_{d, t}-1\right) \text { if } \ell_{d, t}<1
\end{array}\right.
$$

where from (15) and (17), total labor demand $\ell_{d, t}$ equals

$$
\ell_{d, t}\left(=\ell_{p, t}+\ell_{a, t}+\ell_{g, t}\right)=c_{t}\left(\frac{1}{A}+\epsilon h(\tau)\right)+\ell_{g, t}
$$

From (10) and (11), real wage $w_{t}\left(=W_{t} / P_{t}\right)$ is constant over time once $\tau$ is given, and hence the movement of $W_{t}$ represented by (19) yields

$$
\pi_{t}=\gamma\left(\ell_{d, t}-1\right) \text { if } \ell_{d}<1
$$

From (5), (18), (19) and (21), the dynamic equations of $c_{t}$ and $m_{t}$ under full employment are

$$
\begin{aligned}
\eta \frac{\dot{c}_{t}}{c_{t}} & =\frac{v^{\prime}\left(m_{t}\right)}{u^{\prime}\left(c_{t}\right)}-\rho-\pi_{t}, \\
\frac{\dot{m}_{t}}{m_{t}} & =-\pi_{t},
\end{aligned}
$$

while those in the presence of unemployment are

$$
\begin{aligned}
\eta \frac{\dot{c}_{t}}{c_{t}} & =\frac{v^{\prime}\left(m_{t}\right)}{u^{\prime}\left(c_{t}\right)}-\rho-\gamma\left(\ell_{d}-1\right), \\
\frac{\dot{m}_{t}}{m_{t}} & =-\gamma\left(\ell_{d}-1\right) .
\end{aligned}
$$

Hereinafter, we suppress the time index.

\footnotetext{
${ }^{5} \mathrm{~A}$ microeconomic foundation for this wage adjustment is given by Ono and Ishida (2014). It is also assumed by Schmitt-Grohé and Uribe (2016, 2017).
} 


\section{The case of full employment}

If full employment prevails, the total labor demand is $\ell_{d}=1$ in (20), which immediately gives $c$ as a function of $\ell_{g}$ and $\tau$. In this case, the price adjustment is perfect and the dynamics are given by (22), which are the same as in the standard monetary growth model. Thus, the new steady state is immediately reached after policy parameter changes, implying that $\dot{c}$ and $\pi$ in (22) are always zero and that $c$ and $m$ satisfy

$$
c=c^{f}\left(\tau, \ell_{g}\right) \equiv \frac{A\left(1-\ell_{g}\right)}{1+A \epsilon h(\tau)}, \quad \rho=\frac{v^{\prime}(m)}{u^{\prime}(c)} .
$$

From (24), the effects of the environmental policy changes on consumption and real money balances in this state are

$$
\begin{aligned}
\frac{\partial c^{f}\left(\tau, \ell_{g}\right)}{\partial \tau} & =\frac{-A c^{f} \epsilon h^{\prime}}{1+A \epsilon h(\tau)}<0, \\
\frac{\partial c^{f}\left(\tau, \ell_{g}\right)}{\partial \ell_{g}} & =\frac{-A}{1+A \epsilon h(\tau)}<0, \\
\frac{\partial m^{f}\left(\tau, \ell_{g}\right)}{\partial \tau} & =\frac{\rho u^{\prime \prime}}{v^{\prime \prime}}\left(\frac{-A c^{f} \epsilon h^{\prime}}{1+A \epsilon h(\tau)}\right)<0, \\
\frac{\partial m^{f}\left(\tau, \ell_{g}\right)}{\partial \ell_{g}} & =\frac{\rho u^{\prime \prime}}{v^{\prime \prime}}\left(\frac{-A}{1+A \epsilon h(\tau)}\right)<0 .
\end{aligned}
$$

Substituting $c^{f}\left(\ell_{g}, \tau\right)$ in (24) into the net pollution emissions given by (16) yields

$$
z^{f}\left(\tau, \ell_{g}\right)=\frac{(1-\varphi(h(\tau))) \epsilon A\left(1-\ell_{g}\right)}{1+A \epsilon h(\tau)}-\psi\left(\ell_{g}\right)
$$

which satisfies

$$
\begin{aligned}
& \frac{\partial z^{f}\left(\tau, \ell_{g}\right)}{\partial \tau}=-c^{f} \epsilon h^{\prime}\left((1-\varphi) \epsilon\left(\frac{A}{1+A \epsilon h(\tau)}\right)+\varphi^{\prime}\right)<0, \\
& \frac{\partial z^{f}\left(\tau, \ell_{g}\right)}{\partial \ell_{g}}=(1-\varphi) \epsilon\left(\frac{-A}{1+A \epsilon h(\tau)}\right)-\psi^{\prime}\left(\ell_{g}\right)<0 .
\end{aligned}
$$


Because (24) shows $c^{f}$ to be a function of $\tau$ and $\ell_{g}$, employment for private abatement $\ell_{a}$ in (17) is represented as $\ell_{a}=\ell_{a}^{f}\left(\tau, \ell_{g}\right)$. From (25), this function satisfies

$$
\begin{aligned}
& \frac{\partial \ell_{a}^{f}\left(\tau, \ell_{g}\right)}{\partial \tau}=\frac{\epsilon c^{f} h^{\prime}}{1+A \epsilon h}>0, \\
& \frac{\partial \ell_{a}^{f}\left(\tau, \ell_{g}\right)}{\partial \ell_{g}}=-\frac{A \epsilon h}{1+A \epsilon h}<0, \quad \frac{\partial\left(\ell_{a}^{f}\left(\tau, \ell_{g}\right)+\ell_{g}\right)}{\partial \ell_{g}}=\frac{1}{1+A \epsilon h}>0 .
\end{aligned}
$$

Intuitively, an increase in $\tau$ drives firms to reduce pollution emissions by hiring more labor for abatement $\ell_{a}$, which crowds out commodity production and hence $\partial c^{f}\left(\tau, \ell_{g}\right) / \partial \tau<$ 0 (see (25)). An increase in public abatement employment $\ell_{g}$ directly lowers pollution but decreases private abatement. This is because a decrease in consumption due to an increase in $\ell_{g}$ reduces commodity production and private pollution emissions, which makes private abatement less necessary. However, total abatement labor $\ell_{a}+\ell_{g}$ increases, as shown in (27), and net pollution emissions decrease (see (26)), while commodity production is crowded out (see (25)). Therefore, stricter environmental policies have negative welfare effects through reductions in consumption $c$ and real money holdings $m$, and a positive effect through a reduction in pollution $z$.

We summarize the above discussion in the following proposition:

Proposition 1 If full employment prevails, an increase in the emission tax alleviates pollution emissions and lowers commodity production. An increase in employment for public abatement decreases private abatement but the net pollution emissions and commodity production decrease. Thus, the environmental policies create a trade-off between environmental conservation and commodity production. 


\section{The case of stagnation}

Let us now turn to the case in which aggregate demand shortages arise in the steady state. The key assumption is that the desire for money holding is insatiable: ${ }^{6}$

$$
\lim _{m \rightarrow \infty} v^{\prime}(m)=\beta>0
$$

In this case, a full employment steady state exists only if

$$
\rho>\frac{\beta}{u^{\prime}\left(c^{f}\right)} \quad \Leftrightarrow \quad c^{f}<\bar{c} \text { where } \rho=\frac{\beta}{u^{\prime}(\bar{c})}
$$

$\bar{c}$ is the maximum level of consumption that a household chooses under no inflation (or deflation) whereas $c^{f}$, given in (24), is the household's feasible consumption under full employment, which equals its income under full employment.

However, if $c^{f}$ is larger than $\bar{c}$, or equivalently if $c^{f}$ is so large as to satisfy

$$
\rho<\frac{\beta}{u^{\prime}\left(c^{f}\right)}\left(<\frac{v^{\prime}(m)}{u^{\prime}\left(c^{f}\right)} \text { for any } m\right)
$$

there is no solution for the second equation in (24). This property implies that the time preference (i.e., the left-hand side) is less than the liquidity preference (i.e., the righthand side), urging the household to reduce consumption below $c^{f}$ and yielding aggregate demand deficiency and unemployment $\left(\ell_{d}<1\right)$. Therefore, deflation continues, following

\footnotetext{
${ }^{6}$ Using aggregate quarterly data in Japan and Japanese survey data called NIKKEI RADAR, Ono et al. (2004) empirically find this property to be well supported using both parametric and non-parametric methods. Murota and Ono (2011) show that status preference with respect to money plays the same role as a positive lower bound of the marginal utility of money in creating persistent stagnation. Ono and Yamada (2018) propose a model of status preference that works in the same way as the insatiable liquidity preference and apply an experimental method to find the validity of this property. If households regard net wealth (= total wealth minus the present value of future tax payments) as the source of the wealth preference, as assumed by Michau (2018), the marginal utility of wealth is fixed and hence it works as if there is a lower bound of the marginal utility of wealth.
} 


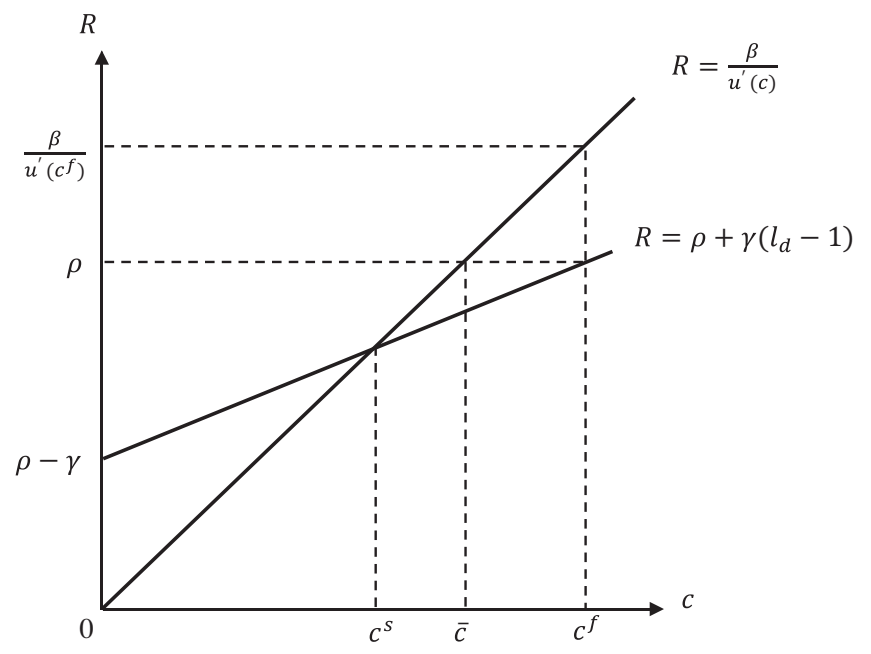

Figure 1: Steady state in a stagnant economy

(21), $v^{\prime}(m)$ approaches $\beta$, and eventually equation (5) reduces to

$$
\frac{\beta}{u^{\prime}(c)}=\rho+\gamma\left(\ell_{d}-1\right)
$$

Figure 1 illustrates the level of $c$ that satisfies (30) in the case where the government employs no labor to abate pollution $\left(\ell_{g}=0\right)$. The dynamics around the steady state are given by (23) and the stagnation steady state is saddle stable as proven in Appendix A.

Under the condition (29), we find

$$
\frac{\beta}{u^{\prime}(c)}\left(=\frac{\beta}{u^{\prime}\left(c^{f}\right)}\right)>\rho+\gamma\left(\ell_{d}-1\right)(=\rho) \quad \text { when } c=c^{f}\left(\ell_{d}=1\right)
$$

For the solution of $c$ in (30) to exist in the range of $\left(0, c^{f}\right)$, it must be valid that

$$
\frac{\beta}{u^{\prime}(c)}(=0)<\rho+\gamma\left(\ell_{d}-1\right)(=\rho-\gamma) \quad \text { when } c=0\left(\ell_{d}=0\right)
$$


or equivalently

$$
\rho-\gamma>0
$$

Furthermore, as is clear from Figure 1, around the steady state the left-hand side of (30) is more inclined than the right-hand side:

$$
\Omega \equiv-\frac{\beta u^{\prime \prime}\left(c^{s}\right)}{\left(u^{\prime}\left(c^{s}\right)\right)^{2}}-\frac{\gamma(1+\epsilon A h)}{A}>0
$$

In this steady state, the transversality condition (6) is satisfied even though $m$ persistently expands. In fact, from (2), when $m \rightarrow \infty$,

$$
\frac{\dot{a}}{a}=\frac{\dot{m}}{m}=-\gamma\left(\ell_{d}-1\right)
$$

Since $\dot{\lambda}=0$ in the steady state, using (30), one obtains

$$
\lim _{t \rightarrow \infty} \frac{\dot{\lambda}}{\lambda}+\frac{\dot{a}}{a}-\rho=-\gamma\left(\ell_{d}-1\right)-\rho=-\frac{\beta}{u^{\prime}\left(c^{s}\right)}<0,
$$

which implies that the transversality condition (6) is valid.

We next examine the effects of environmental policies $\ell_{g}$ and $\tau$ on consumption in the stagnation steady state. As shown in Appendix A, the economy is always in the steady state and hence, we have the following property:

Lemma 1 A new steady state is reached immediately after the environmental policies change.

Taking into account this property, we obtain the consumption level under stagnation, $c^{s}$, for the given $\tau$ and $\ell_{g}$ by substituting (20) into (30). It satisfies

$$
\frac{\beta}{u^{\prime}\left(c^{s}\right)}=\rho+\gamma\left(\left(\frac{1}{A}+\epsilon h(\tau)\right) c^{s}+\ell_{g}-1\right) \Longrightarrow c^{s}=c^{s}\left(\tau, \ell_{g}\right) .
$$


Therefore, the effects of environmental policies $\tau$ and $\ell_{g}$ on consumption $c^{s}$ given above and employment for private abatement $\ell^{a}$ given by (17) are

$$
\begin{aligned}
& \frac{\partial c^{s}\left(\tau, \ell_{g}\right)}{\partial \tau}=\frac{\gamma \epsilon c^{s} h^{\prime}}{\Omega}>0, \quad \frac{\partial c^{s}\left(\tau, \ell_{g}\right)}{\partial \ell_{g}}=\frac{\gamma}{\Omega}>0 \\
& \frac{\partial \ell_{a}^{s}\left(\tau, \ell_{g}\right)}{\partial \tau}=\epsilon c^{s} h^{\prime}\left(1+\frac{\gamma h \epsilon}{\Omega}\right)>0, \quad \frac{\partial \ell_{a}^{s}\left(\tau, \ell_{g}\right)}{\partial \ell_{g}}=\frac{\gamma h \epsilon}{\Omega}>0
\end{aligned}
$$

where $\Omega>0$ as shown by (31). Real money balances $m$ keep expanding because deflation persistently continues in the presence of aggregate demand shortages. An increase in private abatement $\ell_{a}$ caused by the emission tax $\tau$ and an increase in public abatement $\ell_{g}$ create employment and mitigate deflation, which in turn makes holding money less attractive than consumption. Thus, they stimulate consumption, as shown in (33).

This result is opposite to that under full employment mentioned in Proposition 1. Under full employment, the environmental policies crowd out private consumption, whereas under stagnation, they create additional employment and stimulate consumption.

Figure 2 illustrates the effects of the environmental policies on consumption. The upper panel shows the effect of an increase in $\tau$ on $c^{s}$ when $\ell_{g}$ is constant, whereas the lower panel exhibits the effect of an increase in $\ell_{g}$ on $c^{s}$ when $\tau$ is fixed. If $\tau$ and $\ell_{g}$ increase sufficiently to make consumption $c^{s}$ equal $A\left(1-\ell_{g}\right) /(1+\epsilon A h)$ in (32), full employment is reached. That is, $c^{s} \rightarrow \bar{c}$ when $\ell^{d}=1$, as shown in Figure 2. Thereafter, the effects of the environmental policies are as described in Proposition 1.

The environmental policies directly reduce pollution emissions. However, because they create employment and hence consumption and production increase, pollution emissions also increase, and hence firms increase private abatement. Net pollution emissions are the sum of these effects and responses; therefore net pollution emissions may increase or decrease. To show this, substituting $c^{s}\left(\tau, \ell_{g}\right)$ given by (32) into $c$ in (16) yields $z=$ 

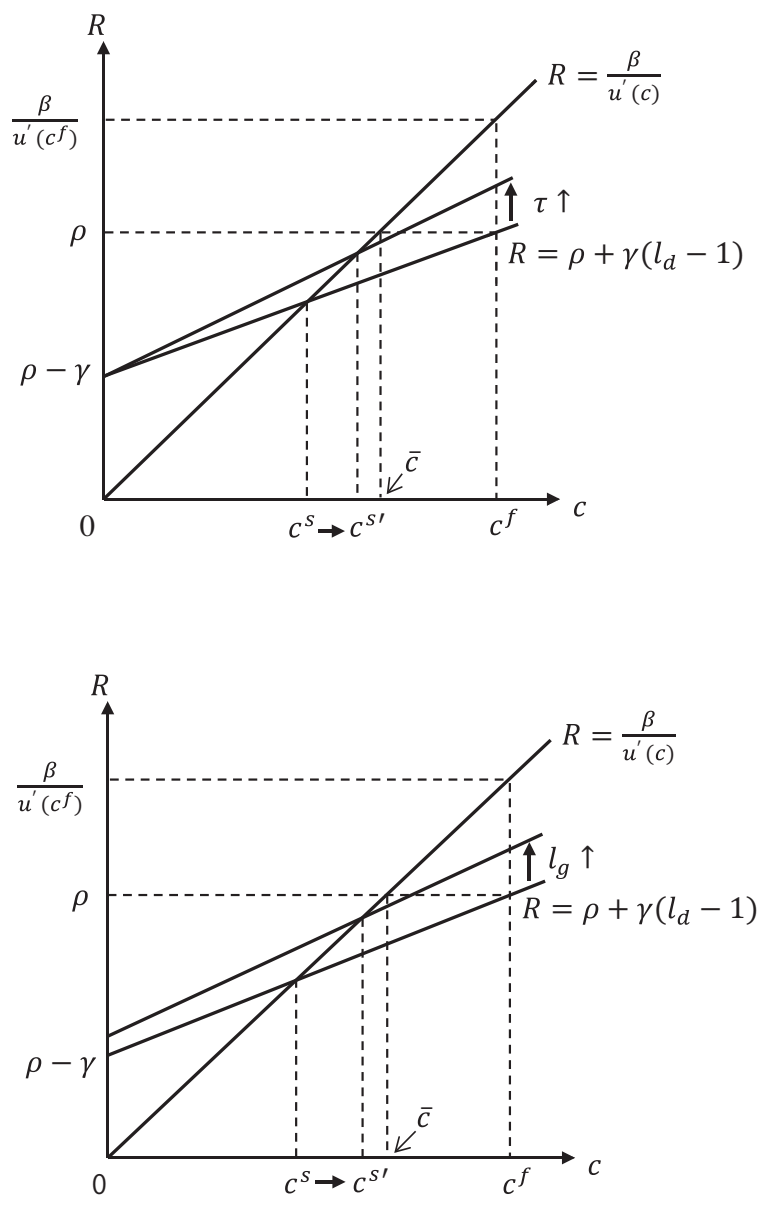

Figure 2: The effects of the environmental policies on consumption in a stagnant economy. $z^{s}\left(\tau, \ell_{g}\right)$. From (33), they satisfy

$$
\frac{\partial z^{s}\left(\tau, \ell_{g}\right)}{\partial \tau}=h^{\prime} \epsilon c^{s}\left(\frac{(1-\varphi) \epsilon \gamma}{\Omega}-\varphi^{\prime}\right), \quad \frac{\partial z^{s}\left(\tau, \ell_{g}\right)}{\partial \ell_{g}}=\frac{(1-\varphi) \epsilon \gamma}{\Omega}-\psi^{\prime}
$$

If the marginal efficiency of private abatement technology $\varphi^{\prime}$ is large (small) enough, a rise in the emission $\operatorname{tax} \tau$ decreases (increases) net emissions. Similarly, if the marginal efficiency of public abatement technology $\psi^{\prime}$ is large (small) enough, more abatement employment by the government decreases (increases) net emissions.

These results are different from those in the case of full employment (see Proposition 
1). In the case of full employment, the environmental policies always reduce pollution emissions by abating pollution and reducing private consumption. In the case of stagnation, they initially reduce pollution but expands abatement employment, which stimulates consumption and production, worsens pollution, and requires additional employment for abatement. If private or public abatement technology is high (low) enough, net pollution emissions decrease (increase).

In sum,

Proposition 2 If (29) holds, secular demand stagnation appears. Then, increasing the emission tax and employing more labor for public abatement expand total employment and mitigate deflation, thereby stimulating consumption. However, the resultant pollution emissions may increase or decrease because increase in consumption creates additional pollution emissions.

By comparing Propositions 1 and 2, we find that the directions of the effects of the environmental policies on consumption under secular stagnation are opposite to those under full employment. Under full employment, the environmental policies crowd out consumption, whereas under stagnation, they increase consumption and commodity production. It is widely believed that there is a trade-off between environmental conservation and commodity production and that this trade-off seems particularly serious under stagnation. However, Proposition 2 shows that under stagnation, stricter environmental regulations stimulate consumption and expand commodity production. Moreover, despite stricter regulations, pollution emissions may expand because of the increase in commodity production. 


\section{Optimal policy mix}

Let us next find the optimal mix of the two policies $\ell_{g}$ and $\tau$. We start the analysis by considering the case in which full employment prevails.

From (14) and (24), $c, m$, and $z$ in the case of full employment are represented as functions of $\tau$ and $\ell_{g}: c^{f}\left(\tau, \ell_{g}\right), m^{f}\left(\tau, \ell_{g}\right)$, and $z^{f}\left(\tau, \ell_{g}\right)$. Thus, welfare (1) is

$$
\begin{aligned}
U^{f}\left(\tau, \ell_{g}\right) & \equiv \int_{0}^{\infty}\left[u\left(c^{f}\left(\tau, \ell_{g}\right)\right)+v\left(m^{f}\left(\tau, \ell_{g}\right)\right)-\delta\left(z^{f}\left(\tau, \ell_{g}\right)\right)\right] e^{-\rho t} d t \\
& =\frac{1}{\rho}\left[u\left(c^{f}\left(\tau, \ell_{g}\right)\right)+v\left(m^{f}\left(\tau, \ell_{g}\right)\right)-\delta\left(z^{f}\left(\tau, \ell_{g}\right)\right)\right] .
\end{aligned}
$$

Using (25) and (26), when $\ell_{g}$ is given, the optimal condition of $\tau$ is

$$
\begin{aligned}
\rho \frac{\partial U^{f}\left(\tau, \ell_{g}\right)}{\partial \tau} & =\frac{c^{f} h^{\prime} \epsilon}{1+A \epsilon h}\left[-A\left(u^{\prime}+v^{\prime} \frac{\rho u^{\prime \prime}}{v^{\prime \prime}}\right)+\left[(1+A \epsilon h) \varphi^{\prime}+A \epsilon(1-\varphi)\right] \delta^{\prime}\right] \\
& =0 \\
& \Rightarrow \tau=\tau\left(\ell_{g}\right) .
\end{aligned}
$$

From (25), (26) and (35), the optimal $\ell_{g}$ with $\tau=\tau\left(\ell_{g}\right)$ satisfies

$$
\begin{aligned}
\rho\left(\frac{d U^{f}}{d \ell_{g}}\right)_{\tau=\tau\left(\ell_{g}\right)} & =\rho\left(\frac{\partial U^{f}\left(\tau, \ell_{g}\right)}{\partial \ell_{g}}+\frac{\partial U^{f}\left(\tau, \ell_{g}\right)}{\partial \tau} \tau^{\prime}\left(\ell_{g}\right)\right) \\
& =\frac{1}{1+A \epsilon h}\left[-A\left(u^{\prime}+v^{\prime} \frac{\rho u^{\prime \prime}}{v^{\prime \prime}}\right)+\left[(1+A \epsilon h) \psi^{\prime}+A \epsilon(1-\varphi)\right] \delta^{\prime}\right] \\
& =\left[\psi^{\prime}\left(\ell_{g}\right)-\varphi^{\prime}\left(h\left(\tau\left(\ell_{g}\right)\right)\right] \delta^{\prime}=0 .\right.
\end{aligned}
$$

Thus, the optimal policy mix $\left.\left(\tau^{f *}, \ell_{g}^{f *}\right)=\left(\tau\left(\ell_{g}^{f *}\right), \ell_{g}^{f *}\right)\right)$ is given by

$$
\varphi^{\prime}\left(h\left(\tau\left(\ell_{g}^{f *}\right)\right)=\psi^{\prime}\left(\ell_{g}^{f *}\right)\right.
$$

Equation (36) implies that the optimal policy mix makes the marginal productivity 
of public abatement equal that of private abatement. To show this, from (15), (16),

and (20) in which $\ell_{d}=1$, pollution emissions $z$ under full employment satisfy

$$
z=\left(1-\varphi\left(\frac{1-\frac{c}{A}-\ell_{g}}{\epsilon c}\right)\right) \epsilon c-\psi\left(\ell_{g}\right) .
$$

Thus, once $c$ is given, $z$ is minimized when

$$
\varphi^{\prime}(h(\tau))=\psi^{\prime}\left(\ell_{g}\right)
$$

which implies (36).

From (24) and (28), if full empolyment prevails with the optimal policy mix given by (36), consumption $c$ must satisfy

$$
c=c^{f}\left(\tau^{f *}, \ell_{g}^{f *}\right) \equiv \frac{A\left(1-\ell_{g}^{f *}\right)}{1+A \epsilon h\left(\tau^{f *}\right)} \leq \bar{c}\left(\equiv u^{\prime-1}\left(\frac{\beta}{\rho}\right)\right) .
$$

However, if $c^{f}\left(\tau^{f *}, \ell_{g}^{f *}\right)>\bar{c}$, the household does not consume up to $c^{f}\left(\tau^{f *}, \ell_{g}^{f *}\right)$. Therefore, the optimal policy mix is such that labor used for commodity production is

$$
\ell_{p}=\frac{\bar{c}}{A}
$$

and that the rest is allocated to the most efficient mix of public and private abatement, as long as full employment is maintained. From (20), in which $\ell_{d}=1$, and (38), the labor allocation is achieved when $\tau$ and $\ell_{g}$ satisfy

$$
\varphi^{\prime}(h(\tau))=\psi^{\prime}\left(\ell_{g}\right), \quad h(\tau) \epsilon \bar{c}+\ell_{g}=1-\frac{\bar{c}}{A} .
$$

We now consider the optimal combination of $\tau$ and $\ell_{g}$ in the case of secular stagnation, where $v^{\prime}(m) \approx \beta$. Suppose that $\left(\tau^{s *}, \ell_{g}^{s *}\right)$ is the optimal combination of $\left(\tau, \ell_{g}\right)$ in this case. 
Then, we have

$$
c=c^{s}\left(\tau^{s *}, \ell_{g}^{s *}\right)<\bar{c}
$$

where $c^{s}\left(\tau, \ell_{g}\right)$ is represented by $(32)$. Because unemployment appears in this state, the government can additionally allocate all the unemployed for private or public abatement, and thereby realize better environment with the same consumption level, $c^{s}\left(\tau, \ell_{g}\right)$, yielding higher utility. Thus, the first-best optimal policy mix is never obtained under stagnation. From (39), once full employment is realized, the optimal policy mix is $\left(\tau^{f *}, \ell_{g}^{f *}\right)$ if $c^{f}\left(\tau^{f *}, \ell_{g}^{f *}\right) \leq \bar{c}$. If not, the optimal policy mix satisfies $(40)$.

We summarize the above discussion as follows:

Proposition 3 The optimal policy mix must accompany full employment. This mix is given by (36) if $c^{f}\left(\tau^{f *}, \ell_{g}^{f *}\right) \leq \bar{c}$. If not, it is given by (40).

\section{Conclusion}

We examine the effects of an environmental tax and employment for public abatement on consumption, pollution, and welfare. If full employment prevails, these policies crowd out consumption, and hence, there is a trade-off between consumption and environmental conservation. In contrast, under secular stagnation of aggregate demand, the policies create employment for private and public abatement and hence stimulate consumption. The stimulated consumption requires larger production, therefore increasing pollution emissions, which may dominate the direct decrease in emissions due to the initial abatement and eventually worsen pollution.

We then examine the first-best optimal mix of the two policies. Under the optimal policy mix, the sum of private and public employment for abatement must be large enough to achieve full employment and the marginal productivity of private abatement must equal that of public abatement. 


\section{Appendix A: Stability}

We first define $x \equiv 1 / m$. Then, the dynamic system can be written as

$$
\begin{aligned}
& \dot{c}=\frac{c}{\sigma}\left[\frac{v^{\prime}(1 / x)}{u^{\prime}(c)}-\rho-\gamma\left(\ell_{d}-1\right)\right], \\
& \dot{x}=x \gamma\left(\ell_{d}-1\right),
\end{aligned}
$$

where $\ell_{d}=(1+\epsilon A h(\tau)) c / A+\ell_{g}$. Applying a first-order Taylor expansion of these equations around the steady state yields

$$
\left[\begin{array}{c}
\dot{c} \\
\dot{x}
\end{array}\right]=\left[\begin{array}{cc}
\frac{c}{\eta}\left(-\frac{\beta u^{\prime \prime}\left(c^{s}\right)}{\left(u^{\prime}\left(c^{s}\right)\right)^{2}}-\frac{\gamma(1+\epsilon A h(\tau))}{A}\right) & -\frac{c}{\eta} \frac{v^{\prime \prime}(1 / x)}{u^{\prime}(c) x^{2}} \\
\frac{x \gamma(1+\epsilon A h(\tau))}{A} & \pi
\end{array}\right]\left[\begin{array}{c}
c-c^{*} \\
x-x^{*}
\end{array}\right] .
$$

The eigenvalues $\nu_{1}$ and $\nu_{2}$ satisfy

$$
\nu_{1} \nu_{2}=\frac{c}{\eta}\left(-\frac{\beta u^{\prime \prime}(c)}{\left(u^{\prime}(c)\right)^{2}}-\frac{\gamma(1+\epsilon A h(\tau))}{A}\right) \pi+\frac{c}{\eta} \frac{v^{\prime \prime}(1 / x)}{u^{\prime}(c) x^{2}} \cdot \frac{x \gamma(1+\epsilon A h(\tau))}{A} .
$$

In the full-employment steady state, $\pi=0$; thus, $\nu_{1} \nu_{2}<0$, which implies that one of the eigenvalues is positive and the other is negative because $v^{\prime \prime}<0$. Since $c$ is jumpable and $x$ is non-jumpable, the steady state is saddle stable.

When stagnation persists, $\ell_{d}<1$ and $\pi<0$ in the steady state and $x$ approaches zero. Hence, from (31), the first term in (A) is negative and the second term is also negative, which implies that the dynamic path is saddle-point stable.

Furthermore, once $v^{\prime}(m)$ approaches $\beta$, the dynamics of $c$ reduce to

$$
\dot{c}=\frac{c}{\sigma}\left[\frac{\beta}{u^{\prime}(c)}-\rho-\gamma\left(\ell_{d}(c, \tau)-1\right)\right] .
$$

Since $c$ is a jumpable variable, the economy reaches the new steady state immediately 
after an exogenous shock

\section{Appendix B: Alternative abatement technology}

In this appendix we assume that the public abatement technology is given by the following homogenous form:

$$
\begin{aligned}
& e_{g}=\Psi\left(\ell_{g}, e_{p}\right)=e_{p} \Psi\left(\frac{\ell_{g}}{e_{p}}, 1\right)=e_{p} \psi\left(\frac{\ell_{g}}{e_{p}}\right), \quad e_{p}=(1-\varphi(h)) \epsilon c \\
& \psi^{\prime}>0, \quad \psi^{\prime \prime}<0, \quad 0 \leq \psi \leq 1, \quad \psi(0)=0, \quad \psi(\infty)=1
\end{aligned}
$$

instead of (13), and show that all three propositions in the text are valid under this technology as well.

Note that neither $c^{f}\left(\tau, \ell_{g}\right)$ given by $(24)$ nor $c^{s}\left(\tau, \ell_{g}\right)$ given by (32) depends on the public abatement technology. Thus, the results regarding the effects of the environmental policies on consumption given by (25) and (33) are valid under this technology.

Under (B1) the amount of net pollution emissions $z$ given by (14) turns to

$$
z=e_{p}\left(1-\psi\left(\frac{\ell_{g}}{e_{p}}\right)\right)
$$

Substituting $e_{p}$ in (B1) to (B2) and partially differentiating the result with respect to $\tau$ and $\ell_{g}$ yields

$$
\begin{aligned}
& \frac{\partial z^{j}\left(\tau, \ell_{g}\right)}{\partial \tau}=\left((1-\psi)+\psi^{\prime} \frac{\ell_{g}}{e_{p}}\right)\left(\frac{(1-\varphi)}{h^{\prime} c^{j}} \frac{\partial c^{j}}{\partial \tau}-\varphi^{\prime}\right) \epsilon c^{j} h^{\prime}, \\
& \frac{\partial z^{j}\left(\tau, \ell_{g}\right)}{\partial \ell_{g}}=(1-\varphi)(1-\psi) \epsilon \frac{\partial c^{j}}{\partial \ell_{g}}-\left(1-\frac{\partial c^{j} / \partial \ell_{g}}{e_{p} / \ell_{g}}\right) \psi^{\prime}, \quad j=f, s .
\end{aligned}
$$

Noting that (25) still holds under full employment, we find $\partial c^{f} / \partial \tau<0$ and $\partial c^{f} / \partial \ell_{g}<0$, and hence, from (B3) $\partial z^{f}\left(\tau, \ell_{g}\right) / \partial \tau<0$ and $\partial z^{f}\left(\tau, \ell_{g}\right) / \partial \ell_{g}<0$. Therefore, Proposition 1 
is valid.

Under stagnation, (33) holds. Substituting $\partial c^{s} / \partial \tau$ in (33) to the first equation in (B3) gives

$$
\frac{\partial z^{s}\left(\tau, \ell_{g}\right)}{\partial \tau}=\left((1-\psi)+\psi^{\prime} \frac{\ell_{g}}{e_{p}}\right)\left(\frac{(1-\varphi) \epsilon \gamma}{\Omega}-\varphi^{\prime}\right) \epsilon c^{j} h^{\prime}
$$

Comparing (B4) with the first equation in (34), we find that the sign is the same between the two. Thus, it can be either positive or negative. Substituting $\partial c^{s} / \partial \ell_{g}$ in (33) to the second equation in (B3) yields

$$
\frac{\partial z^{s}\left(\tau, \ell_{g}\right)}{\partial \ell_{g}}=\frac{(1-\varphi)(1-\psi) \epsilon \gamma}{\Omega}-\left(1-\frac{\gamma}{\Omega} \frac{\ell_{g}}{e_{p}}\right) \psi^{\prime}
$$

If $\ell_{g} \approx 0$, we have $\psi\left(\ell_{g} / e_{p}\right) \approx 0$, and the value of (B5) is the same as $\partial z^{s} / \partial \ell_{g}$ in (34), which can be either positive or negative, as mentioned below (34). Thus, Proposition 2 is valid.

The same logic for the proof of Proposition 3, given above the proposition in the text, still holds. Therefore, this proposition is also valid under the technology represented by (B1).

Thus, all three propositions are valid under the alternative technology of public abatement.

\section{References}

[1] Angelopoulos, K., Economides, G., Philippopoulos, A., 2013. First-and second-best allocations under economic and environmental uncertainty, International Tax and Public Finance 20, 360-380.

[2] Beladi, H., Liu, L., Oladi, R., 2013. On pollution permits and abatement, Economics Letters 119, 302-305. 
[3] Bovenberg, A.L., Heijdra, B.J., 2002. Environmental abatement and intergenerational distribution, Environmental and Resource Economics 23, 45-84.

[4] Bovenberg, A.L., van der Ploeg, F., 1998. Tax reform, structural unemployment and the environment, Scandinavian Journal of Economics 100, 593-610.

[5] Bye, B., 2002. Taxation, unemployment, and growth: dynamic welfare effects of "green"policies, Journal of Environmental Economics and Management, 43, 1-19.

[6] EM-DAT: The Emergency Events Database - Université catholique de Louvain (UCL) - CRED, D. Guha-Sapir - www.emdat.be, Brussels, Belgium.

[7] Fullerton, D., Kim, S-R., 2008. Environmental investment and policy with distortionary taxes, and endogenous growth, Journal of Environmental Economics and Management 56, 141-154.

[8] IMF, 2019. World Economic Outlook: Global Manufacturing Downturn, Rising Trade Barriers. Washington, DC, October.

[9] IPCC, 2014. Climate change 2014: Impacts, adaptation, and vulnerability, Contribution of Working Group II to the Fifth Assessment Report of the Intergovernmental Panel on Climate Change, Cambridge University Press, Cambridge, UK, and New York, NY, USA.

[10] Illing, G., Ono, Y., Schlegl, M., 2018. Credit booms, debt overhang and secular stagnation, European Economic Review 108, 78-104.

[11] Itaya, J., 2008. Can environmental taxation stimulate growth? The role of indeterminacy in endogenous growth models with environmental externalities, Journal of Economic Dynamics \& Control 32, 1156-1180. 
[12] Koskela, E., Schöb, R., Sinn, H-W., 1998. Pollution, factor taxation and unemployment, International Tax and Public Finance 5, 379-396.

[13] Koskela, E. and Schöb, R., 1999. Alleviating unemployment: the case for green tax reforms, European Economic Review 43, 1723-1746.

[14] Ligthart, J.E., van der Ploeg, F., 1999. Environmental policy, tax incidence, and the cost of public funds, Environmental and Resource Economics 13, 187-207.

[15] Mayeres, I., Proost, S., 2001. An economical business-cycle model, NBER Working Paper, No. 19777.

[16] Michaillat, P., Saez, E., 2014. Marginal tax reform, externalities and income distribution, Journal of Public Economics 79, 343-363.

[17] Michau, J-B., 2018. Secular stagnation: theory and remedies, Journal of Economic Theory 176, 552-618.

[18] Murota, R., Ono, Y., 2011. Growth, stagnation and status preference, Metroeconomica $62,122-149$.

[19] Nielsen, S.B., Pedersen, L.H., Sørensen, P.B., 1995. Environmental policy, pollution, unemployment, and endogenous growth, International Tax and Public Finance 2, $185-205$.

[20] OECD 2019. OECD Economic Outlook, Volume 2019 Issue 2: Preliminary version, No. 106, OECD Publishing, Paris, https://doi.org/10.1787/9b89401b-en

[21] Ono. Y., 1994. MONEY, INTEREST, AND STAGNATION: Dynamic theory and Keynes's economics, Oxford: Clarendon Press. 
[22] Ono, Y., 2001. A reinterpretation of chapter 17 of Keynes's general theory: effective demand shortage under dynamic optimization, International Economic Review 42, $207-236$.

[23] Ono, Y., Ishida, J., 2014. On persistent demand shortages: a behavioural approach, Japanese Economic Review 65, 42-69.

[24] Ono, Y., Ogawa, K., Yoshida A., 2004. Liquidity trap and persistent unemployment with dynamic optimizing agents: empirical evidence, Japanese Economic Review 55, $355-371$.

[25] Ono, Y., Yamada, K., 2018. Difference or ratio: implication of status preference on stagnation, Australian Economic Papers 57, 346-362.

[26] Pérez, R., Ruiz, J., 2007. Global and local indeterminacy and optimal environmental public policies in an economy with public abatement activities, Economic Modelling $24,431-452$.

[27] Schmitt-Grohé, S., Uribe, M., 2016. Downward nominal wage rigidity, currency pegs, and involuntary unemployment, Journal of Political Economy 124, 1466-1514.

[28] Schmitt-Grohé, S., Uribe, M., 2017. Liquidity traps and jobless recoveries, American Economic Journal: Macroeconomics 9, 165-204. 